\title{
Parâmetros genéticos da resistência da soja a Cercospora sojina
}

\author{
Geraldo de Amaral Gravina $^{(1)}$, Sebastião Martins Filho(2), Carlos Sigueyuki Sediyama ${ }^{(1)}$ e Cosme Damião Cruz $^{(3)}$
}

(1)Universidade Federal de Viçosa (UFV), Dep. de Fitotecnia, CEP 36570-000 Viçosa, MG. E-mail: gravina@escola24horas.com.br, csediyama@ufv.br (2)Universidade Federal do Espírito Santo, Dep. de Engenharia Rural, CEP29500-000 Alegre, ES. E-mail: smartins@npd.ufes.br (3)UFV, Dep de Biologia Geral. E-mail: cdcruz@ufv.br

\begin{abstract}
Resumo - A herança da resistência da soja a Cercospora sojina Hara foi avaliada por meio de parâmetros genéticos, estimados pela análise de médias e de variâncias de um índice multivariado. Foram utilizados os cruzamentos de duas cultivares resistentes, Paraná (P) e Uberaba (U), com uma suscetível, Bossier (B). Foram avaliados cinco caracteres associados à doença, nos genitores e nas gerações $\mathrm{F}_{1}, \mathrm{~F}_{2}, \mathrm{RCR}$ e RCS de cada cruzamento: nota do grau de infecção avaliado visualmente; diâmetro médio da lesão; porcentagem de área foliar lesionada; número de lesões por centímetro quadrado; e índice de doença. Foi aplicado aos dados das análises de gerações um índice multivariado anteriormente estabelecido. O efeito genético aditivo foi o mais importante na determinação dos caracteres relacionados com a resistência da soja a C. sojina. Nos dois cruzamentos, PxB e UxB, pelo menos um dos tipos de epistasia (aa, ad e dd) foi significativo, sendo mais adequada a avaliação da resistência da soja a $C$. sojina, pelo modelo aditivo-dominante-epistático.
\end{abstract}

Termos para indexação: Glycine max, variáveis canônicas, teste de escala conjunta, índice multivariado.

\section{Genetic parameters of soybean resistance to Cercospora sojina}

\begin{abstract}
The inheritance of soybean resistance to Cercospora sojina Hara was studied based on genetic parameters estimated by the analysis of means and variances of a multivariate index. The crosses between two resistant cultivars, Paraná $(\mathrm{P})$ and Uberaba $(\mathrm{U})$, with a susceptible, Bossier $(\mathrm{B})$, were used. The parents and $\mathrm{F}_{1}, \mathrm{~F}_{2}$, BCR and BCS generations from each cross were evaluated on five characteristics associated to the disease: visually evaluated infection degree; lesion mean diameter; percentage of lesioned leaf area; number of lesions per square centimeter; and disease index. A multivariate index previously established was applied to the data of the generation analyses. The additive genetic effect was the most important in the determination of the characters related to the resistance of soybean to C. sojina. On both crosses (PxB and UxB) at least one kind of epistatic interaction (aa, ad and dd) was significant and the additive-dominant-epistatic model was more adequate to describe the resistance of soybean to C. sojina.
\end{abstract}

Index terms: Glycine max, canonical variables, joint scaling test, multivariate index.

\section{Introdução}

A cercosporiose, ou mancha-olho-de-rã, provocada pelo fungo Cercospora sojina Hara, causa grandes perdas no cultivo da soja, no Brasil. Atualmente, há evidências de 25 raças do patógeno no Brasil e novas raças podem ocorrer (Yorinori \& Klingelfuss, 2000).

A cercosporiose é considerada uma das principais doenças foliares da soja, e também pode atacar o caule, as vagens e as sementes (Akem \& Dashiell, 1994). O controle químico com fungicidas, além de caro, não é o meio mais eficiente para controlá-la. O uso de cultivares resistentes a partir da incorporação de alelos de resistência em cultivares comerciais suscetíveis é o meio mais econômico e eficiente de controle. Para isso, faz- se necessário conhecer o mecanismo de herança do caráter em questão.

Com essa finalidade, a avaliação da natureza e magnitude dos efeitos gênicos, que controlam os caracteres quantitativos associados com a resistência a $C$. sojina Hara, é de grande importância para o melhorista que busca incorporar genes de resistência em cultivares de soja. É fundamental investigar, na fração genética, quais as proporções que podem ser atribuídas aos fatores gênicos aditivos, dominantes e epistáticos. Essas avaliações estão intimamente relacionadas com os objetivos do melhoramento genético (Cruz \& Regazzi, 2001).

Muitas vezes, múltiplos caracteres são afetados pelos genes e, por isso, é necessário mensurar um grande número de variáveis nas populações envolvidas em 
programas de melhoramento. Um dos problemas encontrados quando se trabalha com vários caracteres simultaneamente é conhecer a importância relativa que cada um deles tem em discriminar os tratamentos, podendo-se, com isso, eliminar os caracteres menos importantes para este propósito, os quais, possivelmente, se distinguem por serem invariantes, redundantes, ou já estarem correlacionados a outros caracteres presentes na análise (Martins Filho, 1999).

A análise multivariada, por meio das variáveis canônicas, possibilita determinar a importância relativa dos caracteres, permitindo a simplificação no conjunto de dados, resumindo as informações em poucas variáveis, as quais apresentam a propriedade de reter o máximo da variação originalmente disponível e são independentes entre si. Esta análise foi relatada pela primeira vez por Rao (1952) e pode ser utilizada nos estudos de divergência genética entre indivíduos ou genitores e na determinação da importância relativa de caracteres (Cruz, 2001).

A importância relativa dos caracteres avaliados no material genotípico observado pode ser calculada por meio de coeficientes de ponderação (autovetores) estimados pela técnica de componentes principais ou variáveis canônicas (Mardia et al., 1979). Entretanto, a técnica de variáveis canônicas baseia-se nas informações entre as populações e dentro ou entre indivíduos de cada população, portanto, necessita de dados com repetições. Assim, quando o experimento for realizado em estrutura em que se tem delineamento experimental, pode-se utilizar esta técnica multivariada na eliminação das variáveis menos importantes.

O descarte de caracteres mediante essa técnica multivariada pode ser feito por meio dos maiores coeficientes a eles associados, partindo-se das últimas variáveis canônicas. Após a eliminação de caracteres, a primeira variável canônica envolverá quase toda a variância estimada. Assim, os autovetores da primeira variável canônica associada aos caracteres não eliminados podem ser usados para gerar uma função ou um índice multivariado, que representará o conjunto dos caracteres avaliados no experimento. Esse índice pode ser submetido às análises genético-estatísticas, reduzindo os trabalhos com as análises, economizando tempo e facilitando as conclusões e interpretações dos resultados.

O objetivo deste trabalho foi estudar a resistência da soja a Cercospora sojina Hara, em populações de soja, por meio da obtenção de parâmetros genéticos, com base na análise de médias e de variâncias de um índice multivariado.

\section{Material e Métodos}

O trabalho foi realizado no Departamento de Fitotecnia e no Instituto de Biotecnologia Aplicada à Agropecuária (Bioagro) da Universidade Federal de Viçosa, em 2001.

Dos cruzamentos entre uma cultivar suscetível, Bossier (B), com duas cultivares resistentes, Paraná (P) e Uberaba (U), foram obtidos dois conjuntos de populações: genitores, $\mathrm{F}_{1}, \mathrm{~F}_{2}$, RCS $\left(\mathrm{P}_{1} \times \mathrm{F}_{1}\right)$ e RCR $\left(\mathrm{P}_{2} \times \mathrm{F}_{1}\right)$. Nessas gerações, foram estudadas as reações de resistência à raça 04 do fungo Cercospora sojina Hara, mediante a inoculação nas plantas de soja, em casa de vegetação em delineamento inteiramente casualizado, com número variável de repetições, conforme a população avaliada.

A multiplicação do isolado de $C$. sojina foi feita em placas de Petri, contendo, como meio de cultura, suco de tomate sem tempero e ágar. A inoculação do patógeno foi feita quando as plântulas apresentaram a terceira folha trifoliolada completamente desenvolvida, pulverizando-se cerca de $10 \mathrm{~mL}$ da suspensão de conídios por planta, na concentração de 40.000 conídios por mililitro. A seguir, os vasos foram levados à câmara úmida, onde permaneceram por três dias sob umidade relativa de aproximadamente $100 \%$.

Depois de estabelecidos os sintomas da doença, 20 dias após a inoculação, foram avaliadas as seguintes características: a) grau de infecção (GI) - em escala de notas visuais, variando de 1,0 , sem infecção aparente, até 5,0, máxima infecção; b) número de lesões no folíolo mais infectado da planta (NLF); c) diâmetro médio da lesão (DML) - média das 10 maiores lesões do folíolo mais infectado, em milímetros; d) número de lesões por centímetro quadrado (NLC) - obtido pela divisão do número de lesões pela área do folíolo; e) área foliar lesionada (AFL); f) porcentagem da área foliar lesionada (PAFL) - obtida pela divisão da área foliar lesionada pela área do folíolo e multiplicada por cem; e g) índice de doença (ID) - obtido pelo número de lesões por folíolo multiplicado pelo diâmetro médio de lesão $(\mathrm{cm})$ elevado ao quadrado, ID = NLF x (DML) ${ }^{2}$. Os itens de a até $g$ foram calculados de acordo com Veiga (1973), Cordeiro (1986), Cordeiro et al. (1992) e Martins Filho (1999).

A importância relativa dos caracteres avaliados no material genotípico estudado foi avaliada por meio dos coeficientes dos autovetores estimados pela técnica de variáveis canônicas, por se tratar de experimento realizado numa estrutura de delineamento experimental, em que as populações foram conduzidas com repetições. 
A análise multivariada foi realizada anteriormente com os dados de um experimento com dialelo envolvendo sete genitores de soja e suas combinações híbridas, entre as quais os genitores Bossier, Paraná e Uberaba. As características avaliadas no dialelo também foram as mesmas estudadas neste trabalho. Por isso, o índice multivariado do dialelo foi aplicado aos dados da análise de gerações.

A análise multivariada, por meio das variáveis canônicas, foi utilizada na determinação da importância relativa dos caracteres, permitindo a simplificação no conjunto de dados, resumindo as informações originalmente contidas em poucas variáveis. Esta análise foi realizada pelo aplicativo GENES (Cruz, 2001).

A partir da primeira variável canônica, multiplicaramse seus autovalores associados pelos valores originais das respectivas variáveis consideradas mais importantes, obtendo-se o índice multivariado (caráter composto), representando o conjunto dos caracteres avaliados no experimento.

Os estudos genéticos sobre a herança da resistência da soja a $C$. sojina foram realizados utilizando-se as médias e variâncias das populações estudadas, aplican- do-se ao índice multivariado o teste de escala conjunta de Cavalli (1952), conforme Jinks \& Jones (1958) e Mather \& Jinks (1982). As análises foram realizadas pelos programas computacionais SAS (procedimento GLM), versão 8.0 e do GENES (Cruz, 2001).

\section{Resultados e Discussão}

Após a eliminação das variáveis menos explicativas (NLF e AFL), novas variáveis canônicas foram obtidas com as variáveis mais explicativas, de modo que a primeira variável canônica envolveu mais de $75 \%$ da variância estimada (Tabela1).

A função geradora do índice multivariado, construída a partir dos autovetores da primeira variável canônica, foi: $Y_{i}=1,1344 \mathrm{GI}+0,6155 \mathrm{DML}+0,1265 \mathrm{NLC}-$ 0,0261PAFL - 0,0548ID, em que a variável $Y_{i}$ representa o índice usado na análise do experimento.

Nos dois conjuntos avaliados, genitores resistentes (Paraná e Uberaba) e populações RCR e $\mathrm{F}_{1}$, as médias foram menores do que no genitor suscetível e nas populações RCS, indicando presença de dominância na determinação da resistência ao fungo (Tabela 2). Médias

Tabela 1. Estimativas dos autovalores $\left(\lambda_{j}\right)$ associados às variáveis canônicas e respectivos autovetores, e desvio-padrão residual (S) dos cinco caracteres avaliados no ensaio de reação da soja a Cercospora sojina ${ }^{(1)}$.

\begin{tabular}{ccrrrrr}
\hline$\lambda_{\mathrm{j}}$ & Variância acumulada $(\%)$ & GI & DML & NLC & PAFL & ID \\
\hline 4,9182 & 75,04 & 1,1344 & 0,6155 & 0,1265 & $-0,0261$ & $-0,0548$ \\
0,8850 & 88,54 & $-0,2954$ & $-0,2920$ & $-0,8744$ & $-0,0597$ & 0,4226 \\
0,4292 & 95,09 & $-2,1796$ & 1,2212 & 4,1558 & $-0,3062$ & 0,2991 \\
0,2632 & 99,10 & $-0,8092$ & 1,0942 & $-1,3074$ & 0,0747 & $-0,1222$ \\
0,0588 & 100,00 & $-0,9935$ & 0,2400 & 0,8378 & 0,2818 & $-0,3319$ \\
\hline$S$ & & 0,6928 & 0,8775 & 0,4359 & 6,7631 & 3,9774 \\
\hline
\end{tabular}

${ }^{(1)}$ GI: grau de infecção; DML: diâmetro médio de lesão; NLC: número de lesões por cm²; PAFL: porcentagem de área foliar lesionada; ID: índice de doença.

Tabela 2. Médias $(\hat{\mathrm{m}})$, variâncias $\left(\hat{\sigma}^{2}\right)$ e variâncias das médias $[\hat{\mathrm{v}}(\hat{\mathrm{m}})]$ dos índices multivariados avaliados no ensaio de resistência da soja à Cercospora sojina Hara, nas gerações $\mathrm{P}_{1}, \mathrm{P}_{2}, \mathrm{~F}_{1}, \mathrm{~F}_{2}, \mathrm{RCS}$ e RCR dos cruzamentos Paraná x Bossier $(\mathrm{PxB})$ e Uberaba x Bossier (UxB).

\begin{tabular}{|c|c|c|c|c|c|c|}
\hline \multirow[t]{2}{*}{ População } & \multicolumn{3}{|c|}{ Índice $(\mathrm{PxB})^{(1)}$} & \multicolumn{3}{|c|}{ Índice $(\mathrm{UxB})^{(2)}$} \\
\hline & $(\hat{\mathrm{m}})$ & $\hat{\sigma}^{2}$ & $\hat{\mathrm{v}}(\hat{\mathrm{m}})$ & $(\hat{\mathrm{m}})$ & $\hat{\sigma}^{2}$ & $\hat{\mathrm{v}}(\hat{\mathrm{m}})$ \\
\hline $\mathrm{P}_{1}$ & 4,2013 & 0,28938 & 0,011130 & 4,2014 & 0,28938 & 0,011130 \\
\hline $\mathrm{P}_{2}$ & 2,3348 & 0,32735 & 0,014233 & 1,3430 & 0,04545 & 0,001748 \\
\hline $\mathrm{F}_{1}$ & 2,2985 & 0,52339 & 0,020130 & 2,1894 & 0,56099 & 0,024391 \\
\hline $\mathrm{F}_{2}$ & 2,6086 & 0,86815 & 0,006890 & 2,0418 & 1,02525 & 0,008268 \\
\hline RCS & 2,7405 & 0,87992 & 0,014665 & 2,4247 & 1,74359 & 0,029060 \\
\hline $\mathrm{RCR}$ & 1,7324 & 0,40132 & 0,006802 & 1,2095 & 0,05818 & 0,001293 \\
\hline
\end{tabular}

${ }^{(1)} \mathrm{P}_{1}$ (Bossier), $\mathrm{P}_{2}$ (Paraná), RCS $\left(\mathrm{F}_{1} \mathrm{x}\right.$ Bossier), RCR ( $\mathrm{F}_{1} \mathrm{x}$ Paraná); $\mathrm{P}_{1}\left(\mathrm{~N}=26\right.$ plantas); $\mathrm{P}_{2}(\mathrm{~N}=23) ; \mathrm{F}_{1}(\mathrm{~N}=26) ; \mathrm{F}_{2}(\mathrm{~N}=219) ; \mathrm{RCS}(\mathrm{N}=56) ; \mathrm{RCR}$ $(\mathrm{N}=60) .{ }^{(2)} \mathrm{P}_{1}$ (Bossier), $\mathrm{P}_{2}$ (Uberaba), RCS ( $\mathrm{F}_{1} \times$ Bossier), RCR $\left(\mathrm{F}_{1} \times\right.$ Uberaba); $\mathrm{P}_{1}\left(\mathrm{~N}=26\right.$ plantas); $\mathrm{P}_{2}(\mathrm{~N}=26) ; \mathrm{F}_{1}(\mathrm{~N}=23) ; \mathrm{F}_{2}(\mathrm{~N}=124) ; \mathrm{RCS}(\mathrm{N}=60)$; $\mathrm{RCR}(\mathrm{N}=45)$. 
inferiores, simultaneamente em RCS, na presença de dominância, são esperadas, porque nessas populações ocorre a expressão dos alelos recessivos. Observaramse maiores variâncias nas gerações RCS. Essa maior variância, comparada com as demais gerações, pode ser atribuída à maior segregação dos genes nas gerações RCS e $F_{2}$.

Pelo menos um dos tipos de epistasia (aa, ad ou dd) foi significativa para os dois conjuntos de gerações estudadas, indicando a importância de se utilizar o modelo completo nas suas análises (Tabela 3). Os efeitos genéticos (m, a, d) associados ao modelo simples foram todos significativos. Entretanto, efeitos de dominância e suas interações epistáticas são menores nas espécies autógamas (Brim \& Cockerham, 1961). As técnicas de melhoramento que se beneficiam da alta variância aditiva e da interação aditiva $x$ aditiva, para a obtenção de ganhos genéticos, são mais importantes no melhoramento da soja, por ser esta uma espécie autógama. Como neste trabalho os efeitos aditivos foram significativos, os ganhos preditos com a resistência da soja à manchaolho-de-rã poderão ser alcançados.

A decomposição não é ortogonal, mas a contribuição relativa (CR) provê informação da importância de um particular efeito genético sobre a variabilidade disponível dos caracteres estudados (Tabela 4). Assim, não considerando o efeito da média, o efeito genético mais importante na determinação dos caracteres foi o efeito gênico aditivo $(43,76 \%$ e $87,64 \%$ para os índices PxB e $\mathrm{UxB}$, respectivamente), enquanto o efeito causado pela dominância foi de menor importância, dentre os efeitos simples (m, a, d). Esse fato evidencia a possibilidade de obtenção de materiais homozigóticos superiores, por meio de seleção a partir da geração $\mathrm{F}_{2}$ e que os ganhos nos ciclos de seleção serão satisfatórios, uma vez que o componente de natureza aditiva é de elevada magnitude. As

Tabela 3. Estimativa dos parâmetros genéticos, variâncias e teste t para o modelo completo (aditivo-dominante-epistático), ajustado com base nas médias dos caracteres avaliados, no ensaio de reação a Cercospora sojina Hara, de seis gerações de soja $\left(\mathrm{P}_{1}, \mathrm{P}_{2}, \mathrm{~F}_{1}, \mathrm{~F}_{2}, \mathrm{RCS}, \mathrm{RCR}\right)$ obtidas nos cruzamentos Paraná x Bossier (PxB) e Uberaba x Bossier (UxB).

\begin{tabular}{|c|c|c|c|c|c|c|}
\hline \multirow[t]{2}{*}{ Parametro $^{(1)}$} & \multicolumn{3}{|c|}{ Índice (PxB) } & \multicolumn{3}{|c|}{ Índice (UxB) } \\
\hline & Estimativa & Variância & $\mathrm{t}$ & Estimativa & Variância & $\mathrm{t}$ \\
\hline $\mathrm{m}$ & 4,7675 & 0,20245 & $10,57 * *$ & 3,6708 & 0,25692 & $7,24 * *$ \\
\hline $\mathrm{a}$ & 0,9333 & 0,00634 & $11,72 * *$ & 1,4292 & 0,00322 & $25,19 * *$ \\
\hline $\mathrm{d}$ & $-6,1337$ & 1,29099 & $-5,40 * *$ & $-5,0348$ & 1,67523 & $-3,89 *$ \\
\hline aa & $-1,4884$ & 0,19611 & $-3,36^{*}$ & $-0,8986$ & 0,25370 & $-1,78^{\mathrm{ns}}$ \\
\hline $\mathrm{ad}$ & 0,1495 & 0,11123 & $0,45^{\mathrm{ns}}$ & $-0,4281$ & 0,13429 & $-1,17^{\mathrm{ns}}$ \\
\hline dd & 3,6757 & 0,55961 & $4,91 * *$ & 3,5534 & 0,72838 & $4,16^{* *}$ \\
\hline
\end{tabular}

${ }^{(1)}$ m: média das linhagens homozigóticas derivadas de $\mathrm{F}_{2}$; a: medida do efeito gênico aditivo; d: medida dos desvios da dominância; aa: medida das interações aditivo x aditivo; ad: medida das interações aditivo x dominante; dd: medida das interações dominante x dominante. ns Não-significativo. $*$ e $* *$ Significativo a $5 \%$ e a $1 \%$ de probabilidade, respectivamente.

Tabela 4. Decomposição não-ortogonal da soma de quadrados (SQ) pelo método de Gauss e contribuição relativa (CR) dos parâmetros (m, a, d, aa, ad, dd), para o modelo completo, baseado nas médias das seis gerações $\left(\mathrm{P}_{1}, \mathrm{P}_{2}, \mathrm{~F}_{1}, \mathrm{~F}_{2}, \mathrm{RCS}\right.$ e RCR) no ensaio da reação de soja a Cercospora sojina Hara, obtidas nos cruzamentos Paraná x Bossier (PxB) e Uberaba x Bossier (UxB).

\begin{tabular}{|c|c|c|c|c|}
\hline \multirow[t]{2}{*}{ Fonte de variação ${ }^{(1)}$} & \multicolumn{2}{|c|}{ Índice (PxB) } & \multicolumn{2}{|c|}{ Índice (UxB) } \\
\hline & SQ & CR & SQ & $\mathrm{CR}$ \\
\hline $\mathrm{m} / \mathrm{a}, \mathrm{d}, \mathrm{aa}, \mathrm{ad}, \mathrm{dd}$ & 111,7518 & 35,6003 & 52,4475 & 7,2453 \\
\hline $\mathrm{a} / \mathrm{m}, \mathrm{d}, \mathrm{aa}, \mathrm{ad}, \mathrm{dd}$ & 137,3717 & 43,7619 & 634,4239 & 87,6413 \\
\hline $\mathrm{d} / \mathrm{m}, \mathrm{a}, \mathrm{aa}, \mathrm{ad}, \mathrm{dd}$ & 29,1423 & 9,2837 & 15,1319 & 2,0903 \\
\hline $\mathrm{aa} / \mathrm{m}, \mathrm{a}, \mathrm{d}, \mathrm{ad}, \mathrm{dd}$ & 11,2965 & 3,5987 & 3,1828 & 0,4397 \\
\hline $\mathrm{ad} / \mathrm{m}, \mathrm{a}, \mathrm{d}, \mathrm{aa}, \mathrm{dd}$ & 0,2011 & 0,0640 & 1,3645 & 0,1885 \\
\hline $\mathrm{dd} / \mathrm{m}, \mathrm{a}, \mathrm{d}, \mathrm{aa}, \mathrm{ad}$ & 24,1434 & 7,6913 & 17,3357 & 2,3948 \\
\hline Soma & 313,9069 & 100,0000 & 723,8864 & 100,0000 \\
\hline
\end{tabular}

${ }^{(1)} \mathrm{m}$ : média das linhagens homozigóticas derivadas de $\mathrm{F}_{2}$; a: medida do efeito gênico aditivo; d: medida dos desvios da dominância; aa: medida das interações aditivo x aditivo; ad: medida das interações aditivo x dominante; dd: medida das interações dominante x dominante. 
interações epistáticas aditiva $\mathrm{x}$ aditiva, aditiva $\mathrm{x}$ dominante e dominante $x$ dominante influíram 11,30\% e 3,02\% nos índices PxB e UxB, respectivamente, na determinação das médias das gerações estudadas (Tabela 4). Os resultados indicam que o modelo aditivo-dominante pode explicar a maior parte das variações nesse caráter, em razão da baixa contribuição dos efeitos das interações epistáticas. Entretanto, o uso desse modelo reduzido está sujeito a um viés, já que houve pelo menos um dos tipos de epistasia significativa (Tabela 3) que não deve ser desconsiderado.

Segundo Arias (1986), efeitos de dominância e interações gênicas são de menor importância nas espécies autógamas. Porém, as interações gênicas entre genes não alélicos ou epistáticas não podem ser desconsideradas nos mecanismos genéticos básicos. Modelos genéticos que negligenciam as epistasias podem estar de alguma maneira viesados (Cockerham, 1954).

Em ambos os índices, a média foi o parâmetro de maior valor de estimativa; o efeito gênico devido à dominância foi o parâmetro de maior variância; e todos os parâmetros estimados diferiram significativamente de zero, a $1 \%$ de probabilidade, pelo teste $\mathrm{t}$ (Tabela 5).
O modelo aditivo-dominante possibilita a obtenção de médias preditas que se correlacionam com as médias observadas em magnitudes elevadas em relação aos índices analisados, com correlação de 0,935 para o índice $\mathrm{UxB}$ e 0,948 para PxB (Tabela 6).

$\mathrm{O}$ uso do modelo genético aditivo-dominante foi satisfatório para explicar o comportamento da média das gerações, em relação aos caracteres em estudo. Observou-se que a variabilidade aditiva, presente em $\mathrm{F}_{2}$, é relativamente superior à atribuída aos desvios da dominância nos caracteres avaliados por meio do índice multivariado. Assim, a continuidade do programa possibilitará ganhos com a seleção, a partir da geração $F_{2}$ (Tabela 7).

As estimativas da variância de dominância do índice $\mathrm{PxB}$ foram negativas, devendo ser consideradas nulas (Tabela 8). As estimativas das variâncias aditivas foram positivas, gerando estimativas de herdabilidade em sentido restrito também positivas, indicando presença do efeito gênico aditivo, o mais importante num programa de melhoramento de resistência da soja a $C$. sojina. Observou-se, também, que mais de três genes de resistência estão envolvidos, indicando resistência horizon-

Tabela 5. Estimativas dos parâmetros, suas variâncias e teste t para o modelo aditivo-dominante, obtido com base nas médias de seis gerações de soja $\left(\mathrm{P}_{1}, \mathrm{P}_{2}, \mathrm{~F}_{1}, \mathrm{~F}_{2}, \mathrm{RCS}, \mathrm{RCR}\right)$ avaliadas no ensaio de resistência a Cercospora sojina Hara, obtidas nos cruzamentos Paraná x Bossier (PxB) e Uberaba x Bossier (UxB).

\begin{tabular}{|c|c|c|c|c|c|c|}
\hline \multirow[t]{2}{*}{ Parametro $^{(1)}$} & \multicolumn{3}{|c|}{ Índice (PxB) } & \multicolumn{3}{|c|}{ Índice (UxB) } \\
\hline & Estimativa & Variância & $\mathrm{t}$ & Estimativa & Variância & $\mathrm{t}$ \\
\hline $\mathrm{m}$ & 3,1278 & 0,005225 & $43,27 * *$ & 2,7002 & 0,002900 & $50,51 * *$ \\
\hline $\mathrm{a}$ & 1,0140 & 0,004755 & $14,71 * *$ & 1,4332 & 0,002734 & $27,41 * *$ \\
\hline d & $-1,2497$ & 0,021526 & $-8,52 * *$ & $-1,4175$ & 0,009828 & $-14,30 * *$ \\
\hline
\end{tabular}

${ }^{(1)} \mathrm{m}$ : média das linhagens homozigóticas derivadas de $\mathrm{F}_{2}$; a: medida do efeito gênico aditivo; d: medida dos desvios da dominância. **Significativo a $1 \%$ de probabilidade.

Tabela 6. Médias observadas e estimadas dos índices avaliados nas plantas de seis gerações de soja $\left(\mathrm{P}_{1}, \mathrm{P}_{2}, \mathrm{~F}_{1}, \mathrm{~F}_{2}, \mathrm{RCS}, \mathrm{RCR}\right)$, no ensaio de resistência a Cercospora sojina Hara (modelo aditivo-dominante), obtidas nos cruzamentos Paraná x Bossier (PxB) e Uberaba x Bossier (UxB).

\begin{tabular}{ccccc}
\hline \multirow{2}{*}{ População } & \multicolumn{2}{c}{ Índice $(\mathrm{PxB})^{(1)}$} & & \multicolumn{2}{c}{${\text { Índice }(\mathrm{UxB})^{(2)}}^{\text {Média observada }}$} & Média estimada & & Média observada & Média estimada \\
\cline { 2 - 3 } $\mathrm{P}_{1}$ & 4,2014 & 4,1418 & 4,2014 & 4,1535 \\
$\mathrm{P}_{2}$ & 2,3348 & 2,1137 & 1,3430 & 1,2870 \\
$\mathrm{~F}_{1}$ & 2,2985 & 1,8781 & 2,1894 & 2,0114 \\
$\mathrm{~F}_{2}$ & 2,6086 & 2,5029 & 2,0418 & 2,7281 \\
$\mathrm{RCS}$ & 2,7405 & 3,0099 & 2,4247 & 1,2948 \\
$\mathrm{RCR}$ & 1,7324 & 1,9959 & 1,2095 & \\
\hline
\end{tabular}

${ }^{(1)} \mathrm{P}_{1}$ (Bossier), $\mathrm{P}_{2}$ (Paraná), RCS $\left(\mathrm{F}_{1} \times\right.$ Bossier), RCR ( $\mathrm{F}_{1} \mathrm{x}$ Paraná); $\mathrm{P}_{1}\left(\mathrm{~N}=26\right.$ plantas); $\mathrm{P}_{2}(\mathrm{~N}=23) ; \mathrm{F}_{1}(\mathrm{~N}=26) ; \mathrm{F}_{2}(\mathrm{~N}=219) ; \mathrm{RCS}(\mathrm{N}=56) ; \mathrm{RCR}$ $(\mathrm{N}=60)$; coeficiente de correlação de 0,9487. (2) $\mathrm{P}_{1}$ (Bossier), P2 (Uberaba), RCS $\left(\mathrm{F}_{1} \times\right.$ Bossier), RCR $\left(\mathrm{F}_{1} \times \mathrm{Uberaba}\right) ; \mathrm{P}_{1}(\mathrm{~N}=26) ; \mathrm{P}_{2}(\mathrm{~N}=26) ; \mathrm{F}_{1}$ $(\mathrm{N}=23) ; \mathrm{F}_{2}(\mathrm{~N}=124) ; \mathrm{RCS}(\mathrm{N}=60) ; \mathrm{RCR}(\mathrm{N}=45) ;$ coeficiente de correlação de 0,9350. 
Tabela 7. Decomposição não-ortogonal da soma de quadrados (SQ) pelo método de Gauss e contribuição relativa (CR) dos parâmetros (m, a, d), para o modelo reduzido, com base nas médias das seis gerações de soja $\left(\mathrm{P}_{1}, \mathrm{P}_{2}, \mathrm{~F}_{1}, \mathrm{~F}_{2}, \mathrm{RCS}\right.$ e RCR) no ensaio de reação a Cercosporasojina Hara, obtidas nos cruzamentos Paraná x Bossier (PxB) e Uberaba x Bossier (UxB).

\begin{tabular}{crrrrr}
\hline${\text { Fonte de variação }{ }^{(1)}}^{n}$ & \multicolumn{2}{c}{ Índice $(\mathrm{PxB})$} & \multicolumn{2}{c}{ Índice (UxB) } \\
\cline { 2 - 3 } \cline { 5 - 6 } & \multicolumn{1}{c}{$\mathrm{SQ}$} & $\mathrm{CR}$ & $\mathrm{SQ}$ & \multicolumn{1}{c}{$\mathrm{CR}$} \\
\hline $\mathrm{m} / \mathrm{a}, \mathrm{d}$ & $1.872,2478$ & 86,6360 & & $2.551,6929$ & 72,7510 \\
$\mathrm{a} / \mathrm{m}, \mathrm{d}$ & 216,2516 & 10,0068 & & 751,2468 & 21,4187 \\
$\mathrm{~d} / \mathrm{m}, \mathrm{a}$ & 72,5511 & 3,3572 & & 204,4928 & 5,8302 \\
\hline Soma & $2.161,0505$ & 100,0000 & & $3.507,4325$ & 100,0000 \\
\hline
\end{tabular}

${ }^{(1)} \mathrm{m}$ : média das linhagens homozigóticas derivadas de $\mathrm{F}_{2}$; a: medida do efeito gênico aditivo; d: medida dos desvios da dominância.

Tabela 8. Estimativas das variâncias ambiental, fenotípica, genotípica, aditiva e variância de dominância, herdabilidades em sentido amplo e restrito, grau médio de dominância e número de genes, para os índices multivariados avaliados no ensaio de resistência da soja a Cercospora sojina Hara, obtidos dos genitores (Paraná, Uberaba e Bossier) e suas populações derivadas.

\begin{tabular}{lcc}
\hline Parametro & ${\text { Índice }(\mathrm{PxB})^{(1)}}$ & Índice $(\mathrm{UxB})^{(2)}$ \\
\hline Variância fenotípica & 0,868155 & 1,025250 \\
Variância ambiental & 0,415877 & 0,364206 \\
Variância genotípica & 0,452279 & 0,661044 \\
Variância aditiva & 0,455063 & 0,248730 \\
Variância de dominância & $-0,002784$ & 0,412313 \\
Herdabilidade ampla & 0,520965 & 0,644764 \\
Herdabilidade restrita & 0,524172 & 0,242605 \\
Média dos desvios da dominância $^{(3)}$ & $-1,038900$ & $-0,407763$ \\
Média dos desvios da dominância $^{(4)}$ & $-(5)$ & 1,820909 \\
Número de genes $^{(4)}$ & 3,609600 & 8,119400 \\
\hline
\end{tabular}

(1) Índice $(\mathrm{PxB})$ : índice multivariado obtido pelo cruzamento entre as cultivares de soja Paraná e Bossier. (2)Índice (UxB): índice multivariado obtido pelo cruzamento entre as cultivares de soja Uberaba e Bossier.

${ }^{(3)}$ Calculado com base nas médias. ${ }^{(4)}$ Com base em variâncias. ${ }^{(5)}$ Nãoestimado.

tal. Neste trabalho, as estimativas dos ganhos com a seleção visando a resistência ao patógeno serão maiores nas populações oriundas do cruzamento PxB.

Em materiais selecionados, o efeito gênico aditivo é reduzido, especialmente em relação aos caracteres de herança menos complexa. Nos caracteres quantitativos de herança mais complexa, a contribuição dos efeitos gênicos decorrentes da dominância torna-se maior. Os caracteres governados pela ação gênica por causa da dominância não podem ser fixados e, nesse caso, a exploração da heterozigose é a única solução (Gamble, 1962; Arias, 1986).

O grau médio de dominância, calculado com base em variância, não pôde ser computado em relação ao índice PxB, porque a estimativa da variância decorrente da dominância foi considerada nula. As estimativas calculadas com base em médias não refletem os efeitos da dominância bidirecional (Tabela 8). As estimativas do número de genes que controlam o caráter associado à doença podem não refletir o verdadeiro valor paramétrico, porque o método usado na sua obtenção admite ausência de ligação gênica, ou seja, supõe que todos os locos tenham efeitos iguais e que os genitores sejam contrastantes (Cruz \& Regazzi, 2001). Entretanto, nos índices em que as estimativas foram obtidas, o conjunto gênico envolvido na determinação da resistência da soja à cercosporiose é de mais de três genes.

\section{Conclusões}

1. O efeito genético aditivo é o mais importante na determinação dos caracteres relacionados com a resistência da soja à mancha-olho-de-rã, avaliada pelo índice multivariado.

2. Nas análises dos índices nos conjuntos de gerações de ambos os cruzamentos (Paraná x Bossier e Uberaba x Bossier), as interações epistáticas são significativas em pelo menos um dos tipos de epistasias (aa, ad e dd), sendo a mais adequada na avaliação da resistência da soja a $C$. sojina Hara, pelo modelo aditivodominante-epistático.

\section{Referências}

AKEM, C.N.; DASHIELL, K.E. Effect of planting date on severity of frogeye leaf spot and grain yield of soybeans. Crop Protection, v.13, p.607-610, 1994.

ARIAS, E.R.A. Teste de escala conjunta na estimação de parâmetros genéticos em soja (Glycine max (L.) Merrill). 1986. 86p. Dissertação (Mestrado) - Universidade Federal de Viçosa, Viçosa. 
BRIM, C.A.; COCKERHAM, C.C. Inheritance of quantitative characters in soybeans. Crop Science, v.1, p.187-190, 1961.

CAVALLI, L.L. An analysis of linkage in quantitative inheritance. In: REEVE, E.C.; WADDINGTON, C.H. (Ed.). Quantitative inheritance. London: His Majesty's Stationary Office, 1952. p.135-144.

COCKERHAM, C.C. An extension of the concept of partitioning hereditary variance for analysis of covariance among relatives when epistasis is present. Genetics, v.39, p.859-882, 1954.

CORDEIRO, A.C.C. Herança da resistência da soja (Glycine max (L.) Merrill), a Cercospora sojina Hara, isolado de São Gotardo, Minas Gerais. 1986. 61p. Dissertação (Mestrado) Universidade Federal de Viçosa, Viçosa.

CORDEIRO, A.C.C.; SEDIYAMA, T.; GOMES, J.L.L.; SEDIYAMA, C.S.; REIS, M.S. Herança da resistência da soja a Cercospora sojina Hara, isolado de São Gotardo, Minas Gerais. Pesquisa Agropecuária Brasileira, v.27, p.1035-1042, 1992.

CRUZ, C.D. Programa Genes: versão Windows: aplicativo computacional em genética e estatística. Viçosa: Editora UFV, 2001. $648 \mathrm{p}$.

CRUZ, C.D.; REGAZZI, A.J. Modelos biométricos aplicados ao melhoramento genético. 2.ed. rev. Viçosa: Editora UFV, 2001. 390p.
GAMBLE, E.E. Gene effects in corn (Zea mays L.) - I: separation and relative importance of gene effects for yield. Canadian Journal of Plant Science, v.42, p.339-348, 1962.

JINKS, J.L.; JONES, R.M. Estimation of the components of heterosis. Genetics, v.43, p.223-234, 1958.

MARDIA, K.V.; KENT, J.T.; BIBBY, J.M. Multivariate analysis. New York: Academic, 1979. 521p.

MARTINS FILHO, S. Mancha olho de rã da soja: análise genética e identificação de marcadores moleculares. 1999. 59p. Tese (Doutorado) - Universidade Federal de Viçosa, Viçosa.

MATHER, K.; JINKS, J.L. Biometrical genetics. New York: Chapman and Hall, 1982. 396p.

RAO, R.C. Advanced statistical methods in biometrics research. New York: J. Wiley, 1952. 390p.

VEIGA, P. Cercospora sojina Hara: obtenção de inóculo, inoculação e avaliação da_resistência em soja (Glycine max (L.) Merrill). 1973. 32p. Dissertação (Mestrado) - Escola Superior de Agricultura Luiz de Queiroz, Piracicaba.

YORINORI, J.T.; KLINGELFUSS, L.H. Novas raças de Cercospora sojina em soja. Fitopatologia Brasileira, v.24, p.509-512, 2000.

Recebido em 24 de agosto de 2003 e aprovado em 26 de março de 2004 